\title{
Planejamento da Região Metropolitana de Curitiba como objeto de estudo: análise sobre a produção bibliográfica no período de 1974-2006
}

\author{
Curitiba Metropolitan Region planning as a study object: analysis of literature \\ production from 1974 to 2006
}

Julio Cesar Botega do Carmo

Universidade de São Paulo (USP), São Carlos, SP, Brasil

\section{Resumo}

A partir da divisão em dois momentos (1975-1988 e 1989-2006), o artigo propõe a leitura da produção sobre a Região Metropolitana de Curitiba (RMC) nesse período. Delimitou-se que as pesquisas, no primeiro momento, estivessem centradas sobre as transformações nos espaços urbanos e metropolitanos, como a expansão da urbanização e da industrialização, a institucionalização iniciada no Paraná e em Curitiba, e a ressonância de teorias e contatos com planejadores do exterior. A partir dos anos de 1980, com a redemocratização e as novas condições econômicas, novos temas começaram a ser analisados, como a periferização, as questões sociais e ambientais. Após 1989, recuperaram-se temas e outros novos passaram a ser abordados a partir das condições econômicas e sociais que se colocavam. Busca-se, então, concluir que, mesmo não havendo o reconhecimento do processo de planejamento do município de Curitiba, o planejamento na RMC apresenta lacunas quando se confrontam os estudos sobre o planejamento realizado para as diferentes escalas, seja devido à consolidação de um pensamento hegemônico, que delimita o planejamento metropolitano como problemático, seja pelo fato de haver relação próxima entre a política, sobretudo do município-polo, e a academia, que por diversas vezes corrobora a posição política.

Palavras-chave: Curitiba. Região Metropolitana de Curitiba. Planejamento metropolitano.

\section{Abstract}

This article proposes the reading of the MRC literature in two separate periods (1975-1988 and 1989-2006). The literature about the Metropolitan Region of Curitiba in the analyzed period indicates that the first period focused on changes of the urban and metropolitan areas, such as the expansion of urbanization and industrialization; the institutionalization started in Paraná and Curitiba; theories resonance and contacts with the foreign planners. From the 1980s, with the return of democracy and the new economic conditions, new subjects were analyzed, such as the peripherization, social and environmental issues. The years 1990 and 2000 recovered already discussed subjects and addressed new ones, especially from the economic and social conditions that were placed. The reported scenario conclude that even though not recognized by the Curitiba city planning process, the MRC planning has been object of research, with gaps when compared to planning studies performed in different scales. That is due to either the consolidation of a hegemonic thought that delimitates the metropolitan planning as problematic on one hand, or to the close relationship between politics, especially of the city pole, and academy, which by times, corroborates the political position to other.

Keywords: Curitiba. Metropolitan Region of Curitiba. Metropolitan planning.

JCBC é doutorando em Arquitetura e Urbanismo, e-mail: juliobotega@yahoo.com.br 


\section{Introdução}

Propõe-se, por meio deste texto, a realização de uma revisão sobre a produção a respeito do planejamento metropolitano da Região Metropolitana de Curitiba (RMC), no Estado do Paraná, esforçando-se no sentido de sintetizar um processo de transformação de um território que recebeu atenção singular por parte da academia e técnicos locais. Busca-se inserir o planejamento metropolitano da região nos contextos mais gerais, destacando como diferentes nuances e processos foram trabalhados ao longo do período de 1975 - ano da primeira publicação analisada, um documento elaborado pelo Instituto Universitário de Pesquisas do Rio de Janeiro (IUPERJ), a pedido do Governo Federal sobre o modelo de planejamento urbano de Curitiba, e ano de criação da Coordenação da Região Metropolitana de Curitiba (COMEC) - a 2006 - ano de publicação do segundo Plano de Desenvolvimento Integrado (PDI) da RMC - por uma série de autores.

A análise apresentada tem como diretriz a pesquisa histórica, teórica e/ou crítica por meio da leitura de obras de referência produzidas por técnicos dos órgãos de planejamento e acadêmicos (documentos técnicos oficiais e produção acadêmica). Esses trabalhos, levantados em bibliotecas físicas e digitais dos programas de pós-graduação nas áreas de Ciências Sociais e Humanidades das Universidades de São Paulo, Federais do Paraná, Rio Grande do Sul, Rio de Janeiro, entre outras, bem como dos órgãos de planejamento, como COMEC, Instituto de Pesquisa e Planejamento Urbano de Curitiba (IPPUC) e Instituto Paranaense de Desenvolvimento Econômico e Social (IPARDES), contribuem para o entendimento dos processos de planejamento e metropolização ocorridos na capital do Paraná e sua região desde os anos de 1970, quando passou a ser reconhecida, tomada como objeto a ser estudado e, quando possível, referência a outras localidades ${ }^{1}$. Frisa-se que não se pretendeu esgotar as fontes ou analisar a totalidade das pesquisas; apenas deliberou-se o recorte de algumas das mais representativas e recorrentemente citadas por terceiros.

\footnotetext{
${ }^{1}$ Wilheim (1990, p. 35) destaca que o trabalho realizado em Curitiba foi totalmente pioneiro: "Tanto que, dois anos depois [do Plano de 1966], o SERFHAU me pediu um documento sobre metodologia de planos diretores, para alargar aquela experiência inicial a todo o país. E na verdade toda a orientação sobre como fazer planos se baseou na experiência de Curitiba".
}

\section{A construção de um objeto de estudo: da institucionalização do planejamento metropolitano na RMC (1974) à Constituição Federal de 1988}

Há um aparente consenso entre os autores analisados que as décadas de 1950 e 1960 foram aquelas nas quais o poder público estadual e municipal de Curitiba iniciou a institucionalização do planejamento nas escalas urbana (Curitiba) e regional. Esse processo na capital do Paraná culminou na criação do IPPUC em 1965, cuja função era, entre outras, o planejamento regional e metropolitano, por meio do Setor de Coordenação Regional (SECORE). As primeiras ações do instituto nesse campo foram motivadoras de análises acadêmicas e técnicas na década seguinte, com recorrente citação por terceiros das pesquisas do IUPERJ (1975), de Namur (1976) e de Fernandes (1979). Ainda que formalizada em 1974, a atuação da COMEC não é destacada nessas análises pioneiras.

A principal contribuição dessas pesquisas reside no fato de identificarem as primeiras permanências das diretrizes de desenvolvimento urbano na metrópole, ainda que se atenham, sobretudo, ao uso do solo e à mobilidade. Os trabalhos de Namur $(1976,1992)$ e, principalmente, o documento produzido pelo IUPERJ (1975) destacam e apresentam análises que já incorporavam a dinâmica econômica metropolitana, com o segundo volume do relatório do IUPERJ totalmente dedicado à RMC. A produção desse relatório foi contratada pelo Ministério do Interior para estudar e buscar compreender o planejamento de Curitiba como um caso de sucesso e de modelo a ser ampliado e aplicado em outras cidades do Brasil (IUPERJ, 1975).

A pesquisa de Namur (1976) foi a primeira na academia a incorporar elementos da visão metropolitana em suas análises, ainda que o foco principal tenha sido o processo que levou à criação do IPPUC e seus primeiros anos de atuação. Para a autora, o planejamento metropolitano se apresentava como algo problemático. Notava-se que o planejamento metropolitano era recente, $\mathrm{e}$

[...] apesar de encontrar-se institucionalizado formalmente por leis federais e estatais, não se implementou efetivamente em nenhum Estado brasileiro, devido a grandes dificuldades existentes de caráter político institucional (Namur, 1976, p. 23). 
Observa-se que não existia autoridade executiva na esfera metropolitana, tornando possíveis que as ações fossem implantadas apenas com o consenso dos municípios. Além disso, o planejamento metropolitano, que não possuía poder e recursos próprios, era viabilizado apenas via recursos federais e estaduais, por meio de financiamento e de garantias para empréstimos. 0 planejamento municipal, estadual e nacional, no entanto, contava com instituições próprias e autonomia político-administrativa para atuar.

Destaca-se que, na década de 1970, quando se delimitaram as regiões metropolitanas, o Paraná ainda concentrava a maior parte da sua população no campo. Ao contrário do país, a população urbana só superou a rural na década de 1980 (IBGE, 1970, 1980). A capital vinha perdendo população em relação ao total do Estado, seja por desmembramentos, seja pela ascensão econômica dos municípios do norte paranaense. Entre 1940 e 1960, a perda foi de três pontos percentuais (passou de 11,4\% em 1940 para 8,4\% de participação em 1960). A recuperação, entretanto, foi acelerada nas décadas de 1970 e 1980, quando chegou a 13,6\% da população total do Estado (IBGE, 2010).

A tendência à conurbação e a cada vez maior integração entre os municípios resultaram na delimitação federal da RMC. Por meio da Lei Complementar Federal no 14/1973 (Brasil, 1973), foram estabelecidas oito regiões metropolitanas ${ }^{2}$, com base em um conjunto de estudos encomendados pelo Serviço Federal de Habitação e Urbanismo (SERFHAU) a órgãos locais das diferentes regiões, tais como: as pesquisas do SECORE/IPPUC; o Esboço Preliminar da Divisão do Brasil em Regiões Polarizadas, do Instituto Brasileiro de Geografia e Estatística (IBGE), de 1966; os estudos de Galvão et al. (1969); as publicações do antigo Escritório de Pesquisa Econômica Aplicada (EPEA) e de outras entidades. Um ano depois, a Lei Federal no 20/1974 (Brasil, 1974) estabeleceu a Região Metropolitana do Rio de Janeiro. No ano seguinte, extinguiu-se o SERFHAU e criou-se a Comissão Nacional de Regiões Metropolitanas e Política Urbana (CNPU).

A Lei no 14/1973 definia os serviços públicos de interesse comum (depois transformados em funções pela Constituição Federal de 1988), entre eles o planejamento integrado do desenvolvimento econômico

\footnotetext{
${ }^{2}$ Porto Alegre, Curitiba, São Paulo, Belo Horizonte, Fortaleza, Recife, Salvador e Belém.
}

e social. Além deste, definiam-se como serviços: saneamento básico, notadamente abastecimento d'água, rede de esgotos e serviços de limpeza pública; uso do solo metropolitano; transportes e sistema viário; produção e distribuição de gás combustível canalizado; aproveitamento dos recursos hídricos e controle da poluição ambiental, além de outros serviços incluídos na área de competência do Conselho Deliberativo por lei federal.

Estabelecia também a Lei que cada região metropolitana deveria ter um Conselho Consultivo, um Conselho Deliberativo e uma Secretaria Executiva. Implantados os Conselhos na RMC, parecia natural que a Secretaria Executiva ficasse a cargo do IPPUC, cuja atribuição era, entre outras, a articulação do planejamento local com o regional ${ }^{3}$, algo que o Governo Estadual desejava, mas que não se realizou.

É relevante a recusa do IPPUC em assumir o planejamento na escala metropolitana como Secretaria Executiva, uma vez que o SECORE/IPPUC era tido como órgão de assistência ao planejamento metropolitano, quando da delimitação estadual da RMC em 1967. Em 30 de outubro desse mesmo ano, o Governo Estadual e os municípios próximos à Curitiba estabeleceram um convênio criando a RMC, ainda que a Constituição Federal de 1967 determinasse que tal atribuição pertencia à União. Esse convênio foi ratificado em 1971, e os municípios que assinaram tal termo foram os mesmos definidos pelo IBGE (1966) e que, na Lei Complementar Federal no 14/1973, passaram a conformar a RMC.

Outra análise acadêmica realizada na década de 1970 foi o estudo de Fernandes (1979), que descreve sua pesquisa como

[...] um trabalho sobre planejamento urbano, onde se procura verificar, por meio da descrição do caso de Curitiba, como determinado processo de planejamento local pode ser implementado com sucesso (Fernandes, 1979, p. 2).

De forma recorrente, o autor afirma que Curitiba e o papel do IPPUC revelam uma "bem-sucedida experiência” de planejamento urbano, mas que, até aquele momento, fora pouco analisado, indicando a falta de um quadro teórico de referência para a análise proposta.

\footnotetext{
${ }^{3}$ Lei Ordinária de Curitiba no 2.660, artigo 1, inciso VI, de 01 de dezembro de 1965 (Curitiba, 1965).
} 
O autor, em seu trabalho, buscou caracterizar o caso enquanto único e singular para o contexto brasileiro, principalmente propondo um modelo de análise histórico, baseado, sobretudo, no levantamento documental. 0 autor discute o que seria o planejamento e as suas múltiplas escalas, além dos conflitos decorrentes de tal possibilidade. Sendo ex-técnico do IPPUC e, portanto, tendo participado de forma efetiva do que ocorreu até o momento de sua pesquisa, o texto se atém ao mesmo período do relatório publicado pelo IUPERJ (1975) e ao trabalho de Fachini (1975), ou seja, entre 1965 e 1975.

Característico de sua pesquisa é o não destaque à dinâmica metropolitana. Pelo contrário, esclarece que a dimensão metropolitana de Curitiba foi tida como restrição adotada quando da delimitação de seu tema, sendo assim retirada da discussão, bem como o ambiente político-administrativo e as relações com organismos estaduais e federais de planejamento. É destacada também a já existente incoerência e contradições entre as políticas de desenvolvimento urbano em âmbito local daquela realizada em outras escalas. Sendo assim, a questão metropolitana descrita desta forma por ele:

Acrescente-se ainda [aos problemas relacionados à autonomia municipal] a recente figura do ente metropolitano, que formalmente no caso brasileiro se apresenta simétrico para todo o país, mas na realidade tem apresentado situações bem diferenciadas. E ainda nesse caso a atuação governamental estadual aparece como um complicador de todo o problema, haja visto que a questão urbana se recente nesse nível administrativo, é um tanto fluída ao nível federal, ainda que se antecipando à atuação estadual. (Fernandes, 1979, p. 15).

A leitura dessas obras sobre planejamento metropolitano permite observar que as primeiras contribuições se restringiram, de forma geral, ao município de Curitiba e à primeira década de atuação do IPPUC, devido, sobretudo, à disponibilidade de dados e a um relativo distanciamento, apresentando sumários históricos do planejamento urbano em Curitiba, bem como referenciando modelos teóricos que permitissem tentativas de explicação do caso, além de avaliações acerca do desempenho do instituto (Fachini, 1975; Namur, 1976).
A partir dos anos de 1980, amplificada pela redemocratização e pela legalidade reestabelecida a partidos de esquerda, sindicatos e movimentos sociais, ascendeu a questão social no planejamento. As análises e os documentos sobre a RMC trazem como temáticas o intenso processo migratório, principalmente a partir do norte do Estado, e a falta de infraestrutura e políticas para recebimento e assentamento dessa população, o que levou a periferização da RMC (Gonzáles Osório, 1984; Rolim, 1985; Piragis, 1988; Garcia, 1990).

Após sua estruturação, o órgão de planejamento metropolitano, até o início da década de 1990, realizou uma série de estudos, como o PDI em 1978, o Programa de Investimentos (PI-RMC) em 1987, o Plano de Desenvolvimento Metropolitano (PLAMEC) em 1988, o Plano Metropolitano de Desenvolvimento Integrado (PMDI) em 1990, o Programa de Saneamento (PROSAN) no início dos anos de 1990, entre outros. Contudo, ainda que esses estudos técnicos tenham sido realizados na década de 1980, e para alguns dos projetos, alocados recursos basicamente em sistema viário, houve a desestruturação do planejamento metropolitano, levando a quase extinção da COMEC, em um processo de desmantelamento de instituições federais e estaduais de financiamento e planejamento, além do fim dos impostos direcionados à política de planejamento metropolitano (COMEC, 1999; Borges, 2013). A imprensa destacava que, com o atrofiamento das instituições de planejamento municipal e metropolitano, e de forma a minar as intenções políticas que Jaime Lerner ${ }^{4}$ simbolizava, em 1987 cogitou-se aglutinar o IPPUC com a COMEC, criando a Secretaria da Região Metropolitana, que passaria a ter gestão unicamente estadual, o que não se efetivou (Millarch, 1987).

Nesse contexto, os estudos acadêmicos se assentaram sobre as sucessivas crises econômicas e ascensão da democracia, bem como na formulação de novas diretrizes, com as pesquisas direcionadas a buscar entender as novas condições. A reforma urbana proposta para a Constituição Federal de 1988 encerrava os discursos e o ativismo em favor de uma metrópole que abarcasse uma série de interesses, não apenas priorizando os temas sociais, de forma que, somada à questão social, na década de 1980 e

\footnotetext{
${ }^{4}$ Ex-prefeito de Curitiba e governador do Paraná. No fim da década de 1980, dois adversários políticos de Lerner estavam à frente do executivo estadual e do municipal: Álvaro Dias e Roberto Requião.
} 
início dos anos de 1990, emergiu também a questão ambiental, econômica e demográfica.

Foi um momento caracterizado, sobretudo, por transformações institucionais, em um cenário no qual as relações espaciais de Curitiba e região não eram metropolitanas de forma consolidada, ainda que tendencialmente e institucionalmente já se observasse tal fenômeno. Esse período é marcado por uma tríade de acontecimentos que, juntos, formam um momento de inflexão sobre a realidade metropolitana no Brasil, a saber: o fim dos impostos voltados ao financiamento metropolitano (1984); o fim do Banco Nacional de Habitação (BNH), ao qual se vinculava o SERFHAU e depois a CNPU (1986); a transferência do poder de criação e de delimitação das regiões metropolitanas da União para os Estados, por meio da Constituição Federal de 1988.

Realizaram-se sobre tal contexto trabalhos como os de Namur (1992), que discute a criação e as políticas que possibilitaram o desenvolvimento da Cidade Industrial de Curitiba (CIC) e seus primeiros anos de existência (1973-1980). A autora destaca o papel do Estado e dos empresários na produção do espaço metropolitano, algo que posteriormente foi retomado por Oliveira (2000) e por outros autores. Essa análise buscava identificar os alcances e as limitações atinentes ao planejamento realizado até então no país (Namur, 1992, p. 4).

A originalidade nessa segunda pesquisa de Namur reside na tentativa de compreender a RMC, focando a

[...] preocupação com a compreensão do processo de produção e apropriação do espaço nas cidades brasileiras e do papel do Estado, por meio de suas instituições, nesse processo (Namur, 1992, p. VI).

O momento de instalação da CIC, predefinida em 1972 (Lei Municipal no 4.199/1972, artigo 10), implementada a partir de 1973 e institucionalizada em 1974 (por meio da Lei Municipal no 4.772/1974), encontrava-se em um período marcado pela ação estadual como indutor e financiador da industrialização na RMC (Namur, 1992, p. 5). A autora pretendia analisar o processo pelo qual se produziu a CIC por meio da ação do Governo Estadual e das instituições públicas de planejamento e de prestação de serviços (como telefonia e energia).

Os trabalhos abordam ainda as relações entre qualidade de vida e o processo de planejamento, reflexos do projeto político instalado e como problemática diretamente relacionada às questões sociais e ambientais contemporâneas. A integração do transporte urbano da RMC, a periferização e a sistemática ocupação de áreas de mananciais - e os decorrentes danos ambientais e sociais de tal prática - produziram um cenário de preocupação com a questão socioambiental, aderindo uma nova escala de análise, a da região metropolitana.

0 modelo de planejamento adotado na escala metropolitana e o papel da instituição de planejamento continuaram, contudo, como coadjuvantes das discussões geralmente realizadas como decorrentes dos processos que aconteciam dentro dos limites do município de Curitiba. Nesse período, por exemplo, como aponta Leitão (2010), surgiu o discurso da "Capital Ecológica”, capitaneado pelo então prefeito Jaime Lerner. Tal discurso contrasta com o que ocorreu na prática, quando se intensificaram as ocupações irregulares da RMC (Polli, 2006), em sua maioria sobre as áreas de mananciais, as quais só teriam regulamentação a partir de 1998 pelo poder estadual, mas que foram de forma recorrente ignoradas, seja pelas pessoas de baixa renda, seja pelo grande capital, sobretudo internacional, que se instalou nos anos de $1990 \mathrm{em}$ tais áreas. Ainda que o discurso tenha sido proferido pelo prefeito responsável por Curitiba, a magnitude das ações tomadas no âmbito do município-polo tem impactos, positivos ou negativos, sobre os demais municípios.

Portanto, ainda que recorrente na literatura, essa impressão da polarização entre um centro rico (Curitiba) e a periferia pobre (restante da RMC) seria redutora, pois a periferia também existe dentro dos limites político-administrativos de Curitiba, o que implica em reconhecer uma parte da cidade como um todo, o que não encontraria respaldo na realidade. Esse quadro corrobora o apontado por Lencioni (2011), que destaca que a já desgastada teoria centro-periferia, historicamente aplicada à realidade latino-americana, já não faz sentido devido aos cada vez mais complexos conflitos multiescalares.

Avançando para os anos de 1990, houve uma nova onda de investimentos do Estado, como ocorrera na década de 1960 e 1970 com a capital, mas nesse novo momento tendo como espaço privilegiado alguns municípios metropolitanos. Visando, sobretudo, à atração e implantação de investimentos da indústria automobilística e, posteriormente, no setor de serviços, comércios e transporte, aprofundou-se o processo 
de industrialização, dessa vez com indústrias de alta tecnologia, ao mesmo tempo que o setor terciário emergiu como principal setor econômico na capital, consolidando a reestruturação produtiva da região. De acordo com Borges (2013, p. 120), após as dificuldades dos anos de 1980, esse período foi de fortalecimento do órgão metropolitano e, na escala municipal de Curitiba, o IPPUC voltava ao lugar de destaque que tivera até 1983.

\section{O metropolitano como escala de análise entre 1989 e 2006}

O segundo período é compreendido entre 1989 e 2006, momento em que autores como Firkowski (2009a) identificam as transformações espaciais que consolidaram o fenômeno da metropolização na região de Curitiba, quando a RMC, que era um ente meramente institucional, passou a ter características que a qualificavam verdadeiramente como uma região metropolitana. Essa transformação tem como ponto de partida o marco de mudança que a Constituição Federal de 1988 representou e que se encerra no ciclo 2004 - quando foi adaptado o Plano Diretor de Curitiba ao Estatuto da Cidade de 2001, destacando a necessidade de uma articulação em escala metropolitana - a 2006 - quando da publicação do segundo PDI da RMC pela COMEC (Paraná, 2006).

É necessário lembrar que a realidade brasileira aponta para duas faces dessa unidade de planejamento enquanto tema a ser analisado: de um lado, a figura institucional, imposta por leis, e, de outro, o fato metropolitano em si, a aglomeração urbana, com suas relações, dinâmicas e fluxos eminentemente metropolitanos. Como aponta Firkowski (2009b, p. 158), a transferência da responsabilidade pela política metropolitana do âmbito federal para o estadual gerou um quadro no qual os Estados passaram a criar regiões e inserir municípios nelas, mas sem dinâmicas que caracterizassem uma região metropolitana. Dessa forma, convencionou-se, entre uma série de autores, separar o estudo da unidade institucional daquela na qual de fato ocorrem dinâmicas de natureza metropolitana.

Com esse cenário, as referências bibliográficas sobre os anos de 1990 têm forte tônica na reestruturação produtiva da metrópole, com o empresariamento urbano, a seletividade na ocupação dos espaços e a inclusão parcial de populações até então excluídas, que marcaram a RMC, principalmente com a integração da rede de transporte metropolitano, a chegada de grandes montadoras de automóveis e amplos investimentos, especialmente nos municípios de São José dos Pinhais e, ainda que efêmero, de Campo Largo. A reestruturação econômica e o discurso ecológico, bem como novas leis, foram ponto de partida de um processo que culminou na revisão dos mais importantes documentos de planejamento da cidade e da região metropolitana no limiar do século XXI.

Portanto, houve um redirecionamento de análises e de pesquisas sobre a dinâmica regional e metropolitana na RMC durante esse período. A partir do final dos anos de 1980, um esforço, no sentido de compreender as dinâmicas metropolitanas no Brasil e no Paraná, levou à criação e à organização de fóruns de debate e de pesquisa sobre as regiões metropolitanas, além das pesquisas universitárias, que passaram a dirigir estudos nesse sentido. Cabe destacar que foi somente após esse momento que as pesquisas acadêmicas passaram a ser majoritariamente realizadas em instituições universitárias situadas em Curitiba. Até então, a maior parte da contribuição acadêmica provinha de instituições diversas, de diferentes localidades, principalmente São Paulo, Rio de Janeiro e Porto Alegre.

0 resgate por organismos internacionais, como a OCDE (2001a, b), e a ascensão de governos trabalhistas no Brasil a partir de 2003, resultaram em um certo direcionamento das pesquisas sobre a gestão metropolitana para as análises acadêmicas. Na RMC, a criação e a consolidação dos programas de pós-graduação em Geografia da Universidade Federal do Paraná (UFPR) e de Gestão Urbana da Pontifícia Universidade Católica do Paraná (PUC-PR) ampliaram o número de pesquisas, como o trabalho de Schussel (2006), ex-técnica da COMEC, que discute as tendências contemporâneas de planejamento na aglomeração metropolitana de Curitiba.

Surgiram, desse esforço coletivo, trabalhos como o da série "Conjuntura Urbana", conduzido pelo Observatório das Metrópoles, que tem um volume dedicado à RMC. Esse estudo foi coordenado na RMC pela geógrafa Rosa Moura, ex-pesquisadora do IPPUC, COMEC e IPARDES, autora de uma série de textos que auxiliam na compreensão de Curitiba e da RMC. Em parceria com Ultramari (Ultramari \& Moura, 1994), publicou a primeira obra de síntese e 
que permanece uma das principais referências sobre o planejamento metropolitano na RMC, situando o processo de metropolização pelo qual passava Curitiba e região metropolitana, destacando aspectos sociais como o incremento demográfico e a periferização da metrópole. Os dois autores já haviam publicado artigos sobre a RMC em eventos e periódicos, e a publicação que se refere aqui é a do trabalho consolidado de ambos como ex-técnicos da COMEC e que estavam naquele momento ligados ao IPARDES. Vale destacar que esse instituto foi o primeiro a elaborar documentos, tendo como recorte a RMC após a institucionalização das regiões metropolitanas, antecipando-se mesmo à COMEC.

Ao contrário dos autores que escreveram sobre o IPPUC e o planejamento urbano de Curitiba, as primeiras obras sobre o planejamento metropolitano não a citam como referência. Duas décadas separam a criação do órgão metropolitano dessas primeiras análises sobre o planejamento metropolitano, por isso os resultados apresentados são bem diferentes daqueles que analisaram o IPPUC.

Esse resgate da questão metropolitana ocorreu a partir das alterações que elevaram Curitiba ao posto de segundo maior polo automotivo do Brasil, além da metropolização da sua população, multiplicada cinco vezes desde os anos de 1970. Para Garcia (1993), a volta de Lerner ao poder executivo municipal e depois ao estadual nos anos de 1990, marcou o ressurgimento e a revalorização do planejamento, sob os auspícios do planejamento estratégico ${ }^{5}$. Para a autora, inspirado nas experiências de Barcelona para as Olimpíadas de 1992, o planejamento entrou em uma nova fase, sob novos paradigmas, como a sustentabilidade, a competição em um mercado mundial de cidades e a metropolização. Acompanhando o processo urbano-industrial pelo qual passou o Brasil no século XX e com a derrocada dos governos militares na década de 1980, a partir dos anos de 1990, esse paradigma e essa forma de planejar ganharam espaço, tornando-se, assim, uma espécie de consenso entre uma série de pesquisadores, planejadores e governantes. Para ela, tal forma de planejamento encontrou terreno fértil nas regiões metropolitanas brasileiras, áreas do território com maior desenvolvimento tecnológico e a capacidade de absorver as demandas que o modelo pressupõe.

\footnotetext{
${ }^{5}$ Como visto, Fernandes (1979) já identificava o modelo de planejamento urbano de Curitiba com esse "novo paradigma" já na década de 1970.
}

Com um distanciamento histórico maior em relação aos trabalhos da década de 1970, Oliveira $(1995,2000)$ realizou a análise das relações entre a política, o empresariado e o desenrolar do processo de planejamento. 0 autor destaca a inserção institucional do planejamento e do urbanismo como representação dos interesses muitas vezes particulares em detrimento do interesse público. Seu recorte espacial é o município de Curitiba, mas, em diferentes momentos, aborda os desdobramentos de tal política e seus efeitos no espaço metropolitano, atendo-se ao período entre 1965 e meados dos anos de 1990. Sua pesquisa foi parcialmente complementada por Nazareno (2005), que realizou análises no mesmo sentido, focando no período entre 1985 e 2004, com interesse maior nas redes políticas do que no papel institucional do planejamento, sobretudo do grupo Lernista na prefeitura e governo estadual.

Identifica-se que, nas produções, temas já latentes nos anos de 1970 voltaram ao centro do debate com novas abordagens, como a avaliação da atuação dos órgãos de planejamento e a temática social. A análise de autores como Albuquerque (2007) e Leitão (2002, $2010)^{6}$ aborda o planejamento por meio do conceito de ideologia, ou seja, a vinculação de ideia e de imagem a um discurso altamente efetivo que os levou a criticar a omissão da questão habitacional no conteúdo dos planos elaborados, os simplificados pressupostos sociais. A análise da autora mostra a evolução dos problemas sociais, identificando o crescimento acelerado das ocupações irregulares nos anos de 1970, 1980 e início dos 1990. Contudo, demonstra que, a partir de determinado momento, as ocupações passaram a ser mais recorrentes na RMC, com a diminuição da participação de Curitiba. Ela expõe que, aparentemente, o decréscimo das ocorrências de ocupação irregular em Curitiba aponta que a informalidade da moradia na RMC começou a se transferir da "cidade-modelo" para os demais municípios do Núcleo Urbano Central (NUC) (Albuquerque, 2007, p. 48; Pilotto, 2010, p. 51).

A periferização, prosseguindo na linha das pesquisas sobre a questão habitacional, é um dos focos de análise desenvolvidos por Polli (2006), quando discute a RMC se utilizando do instrumental oferecido por Santos (1990) e de suas análises sobre o que denominou

\footnotetext{
${ }^{6}$ Ainda que os trabalhos de autores como Leitão (2010) e Albuquerque (2007) extrapolem o período de análise proposto, tais pesquisas foram consideradas, uma vez que o recorte temporal ao qual se referem é contemplado pelo artigo.
} 
de metrópole corporativa. A autora expõe a dialética existente entre a metrópole espetáculo, materializada em condomínios fechados, e a metrópole real, na qual o processo de origem de habitações de baixo padrão é o recorrente.

Também no campo social, o trabalho de Leitão (2010) diferencia o planejamento praticado nas décadas de 1960 e 1970, de desenvolvimentismo e patrocínio estatal, daqueles nos anos de 1980, da periferização e radicalização dos sindicatos e movimentos sociais em prol da democracia. A democratização do espaço urbano também passou a ser objeto de análise enquanto fruto de uma ideologia que passou a priorizar o empresariamento urbano - e que ressignificou a economia por meio da nova reestruturação produtiva nos anos de 1990. A autora evidencia que houve uma evidente seletividade na ocupação dos diferentes grupos sobre o espaço metropolitano, propondo uma forma de análise em que a expansão urbana se deu pela lógica de inclusão de populações ignoradas, sobretudo por meio das políticas de transporte, mas que automaticamente reproduziu em escalas cada vez maiores a proporção de excluídos.

Ainda na emergência de temas ambientais e sociais, produziram-se trabalhos como os de Hardt (2004), Lima (2000), Deschamps (2004), entre outros, que enfocaram a questão socioambiental, na esteira da discussão sobre desenvolvimento sustentável, em voga no início do século. Deschamps (2004) defende, por exemplo, a tese da distribuição desigual dos danos ambientais, variando com o grupo social, bem como a expansão urbana e a ocupação de áreas periféricas e ambientalmente frágeis como única alternativa às camadas mais pobres da população. Atingindo também os migrantes, expõe que uma série de problemas de ordem material e mesmo a dificuldade de acesso aos serviços públicos são característicos desse processo. Rickli (2012) também discutiu os embates entre ocupação e uso de recursos ambientais, em uma perspectiva de confrontar as ações culturais humanas com as de proteção à natureza. Todas essas pesquisas têm como estudos de caso a RMC.

Além do foco no ambiental, no social e no econômico, os anos de 2000 trouxeram novamente para o centro da discussão pública a gestão territorial, após o processo de metropolização da RMC se consolidar (Ultramari \& Moura, 1994), partindo de novas condições, como a formulação do PDI (2002/2006) metropolitano, a incorporação de temáticas metropolitanas à revisão do Plano Diretor de Curitiba (1997/2004), que o adequou ao Estatuto da Cidade de 2001, e a consolidação da Associação de Municípios da Região Metropolitana de Curitiba (ASSOMEC), criada em 1982, mas efetivada a partir de 2001. Além desses marcos, houve a incorporação da temática metropolitana em diversas leis estaduais e municipais; até mesmo uma pretensa Lei Estadual sobre delimitação e gestão das regiões metropolitanas foi elaborada nesse período ${ }^{7}$.

As questões metropolitanas assumiram então um papel preponderante na pauta das discussões, levando sua gestão a ser identificada como um processo coletivo a fim de obter algum sucesso (COMEC, 1999). Dessa forma, além desses autores já situados, outras pesquisas se dedicaram ao estudo de Curitiba sob o ponto de vista dos processos de metropolização e planejamento da região metropolitana.

Entre eles, Firkowski (2009a) expõe que foi a partir da década de 1990, sobretudo a partir de 1995, que Curitiba passou a se configurar realmente como região metropolitana, a despeito da institucionalização ter se dado cerca de duas décadas antes. A autora afirma que:

É como se, de repente, tudo o que existia na cidade em termos de comércio e serviços tivesse que ser reformulado, de modo a se ajustar ao novo momento econômico e à nova dimensão de cidade, qual seja a metrópole. A metrópole passa a ser a referência, e as novas demandas devem ser atendidas por empresas que se relacionem a um novo paradigma, sendo mais modernas, eficientes, representativas de um mundo globalizado e, por consequência, internacional (Firkowski, 2009a, p. 39).

A autora aponta ainda que foi na inter-relação entre a produção de uma imagem positiva, alavancada por um processo interno de planejamento urbano de forma contínua, desde a década de 1960, somada à atratividade e à implantação de uma série de indústrias de capital internacional, que a RMC se inseriu como território privilegiado de negócios. Contudo, a internacionalização da sua imagem só se concretizou com os grandes capitais internacionais, sobretudo com as montadoras de veículos que se instalaram na região, a partir de 1995. A chegada do capital ligado

\footnotetext{
${ }^{7}$ Lei Complementar Estadual n. 111/2005 (Paraná, 2005).
} 
às indústrias automobilísticas na década de 1990 simbolizou o novo momento da dinâmica econômica, pois encontrou no aglomerado metropolitano, um local fértil para sua reprodução. Ocupando o espaço em rede, as montadoras foram acompanhadas de uma série de indústrias e de estabelecimentos menores que tinham participação direta na linha de montagem dos automóveis.

Ultramari \& Moura (1994) prosseguem como referência sobre o estudo da RMC, publicando vários resultados de pesquisas dispostos, sobretudo, em artigos. Ultramari $(2001,2005)$ publicou em 2005 o resultado da sua tese, discutindo o terceiro setor e o papel das agências de financiamento, tendo como recorte de estudo as práticas realizadas na RMC.

Em sua tese, Moura (2009) defendeu a particularidade da organização territorial do Estado do Paraná, identificando o que denominou de "arranjos urbanoregionais" como "categoria espacial ligada à urbanização contemporânea", relacionados "às dinâmicas territoriais inerentes aos estágios mais avançados de inserção na divisão social do trabalho" (Moura, 2009). Tratase de um novo conceito e de uma nova categoria, dos quais concentração, conhecimento, mobilidade, conectividade e proximidade são elementos flagrantes e determinantes de sua condição.

Em texto anterior, Firkowski (2001) apresentou a discussão do processo de metropolização de Curitiba enquanto fruto da aceleração da urbanização que levou à institucionalização da RMC, discutindo também o que denominou de ações do planejamento urbano em Curitiba e as intenções do planejamento metropolitano na RMC. A autora, além de discutir o processo de metropolização, analisa o chamado aglomerado metropolitano e a nova distribuição da indústria, com foco na atividade automobilística. A autora expõe que o período compreendido entre o início dos anos de 1970 até o final dos anos de 1980 desencadeou o processo de concentração econômica e populacional em Curitiba. A partir desse momento, seu espaço urbano teria sido sistematicamente estruturado por meio de um ininterrupto processo de planejamento, alterando as características econômicas da cidade e da região, auxiliando, assim, a compreensão das atuais transformações (Firkowski, 2001, p. 27).

Outro tema que retornou às pesquisas nos anos de 2000 foi o discurso social como função do planejamento. Essa temática emergiu no início da década de 1980, mas, já em 1974, Fachini realizara um levantamento sobre as demandas sociais do município de Curitiba. Tal assunto foi recuperado como parte dos movimentos que exigiam a redemocratização e o combate às desigualdades e à pobreza em que se encontrava boa parte da população. Questionava-se a apropriação da ideia de desenvolvimento, aplicada e aprovada pelas elites políticas e econômicas locais, da qual decorreu a seletividade na ocupação do espaço metropolitano, gerando contradições no próprio alcance do sistema capitalista, que integra e desintegra espaços, processos e pessoas, incluindo e excluindo ao mesmo tempo.

\section{Considerações finais}

Com esta revisão da bibliografia é possível observar que, dos trabalhos pioneiros aos temas atuais, diferentes métodos e abordagens, vindas de contribuições de diversos campos do conhecimento, permitiram a construção do referencial sobre o planejamento metropolitano da RMC. Com as novas possibilidades que se abriram diante dos processos de acesso à informação e com a criação e consolidação de cursos de pós-graduação e de instituições e centros de pesquisas, uma miscelânea de temas passou a ser abordada, recuperando assuntos antigos e estudando a realidade corrente ou ainda as perspectivas futuras.

Percebe-se, com esse cenário, que os estudos sobre o planejamento metropolitano na RMC abrangeram a discussão econômica, populacional e de industrialização, temáticas motivadas pela inserção da região em novas cadeias produtivas e no mercado internacional ao longo do período. Portanto, de forma geral, as análises se centraram: a) no processo de metropolização; b) na institucionalização do planejamento e c) na análise da região com um olhar a partir das ações realizadas no município-polo.

Sob este terceiro tópico, é latente a lacuna existente no confronto entre o planejamento realizado para as diferentes escalas, seja devido à consolidação de um pensamento hegemônico que delimita o planejamento metropolitano, enquanto problemático, e o planejamento urbano de Curitiba como modelo. Observa-se que, historicamente, as produções sobre o planejamento urbano de Curitiba e o IPPUC contrastam com a atenção dispensada ao planejamento metropolitano da RMC e a atuação da COMEC, com poucas referências sobre tais, com exceção da história oficial e legal. 
Pretende-se, por meio deste texto, chamar atenção à atualidade do tema, buscando contribuir no preenchimento dessa lacuna com pesquisas que, partindo da bibliografia existente, preocupem-se em retratar o planejamento de ambas as escalas como um processo complexo e multiescalar, não apenas baseado nos problemas decorrentes do planejamento ou da falta dele, mas também na prática existente, sobretudo do planejamento metropolitano.

\section{Referências}

Albuquerque, A. F. (2007). A questão habitacional em Curitiba: o enigma da "cidade - modelo" (Dissertação de mestrado). Faculdade de Arquitetura e Urbanismo, Universidade de São Paulo, São Paulo.

Borges, W. A. (2013). Gestão Metropolitana: sua construção a partir de duas experiências de associativismo territorial na Região Metropolitana de Curitiba (Tese de doutorado). Programa de Pós-graduação em Administração, Fundação Getúlio Vargas, São Paulo.

Brasil. (1973, 11 de junho). Lei Complementar Federal no 14, de 8 de junho de 1973. Estabelece as Regiões Metropolitanas de São Paulo, Belo Horizonte, Porto Alegre, Recife, Salvador, Curitiba, Belém e Fortaleza. Brasília: Diário Oficial da União.

Brasil. (1974, 1 de julho). Lei Complementar Federal no20, de 1 de julho de 1974. Dispõe sobre a criação de Estados e Territórios, inclusive sobre a criação da Região Metropolitana do Rio de Janeiro. Brasília: Diário Oficial da União.

Coordenação da Região Metropolitana de Curitiba - COMEC. (1999). Metrópolis em revista (Vol. 1). Curitiba: COMEC.

Curitiba. (1965, 1 de dezembro). Lei Ordinária de Curitiba no 2.660, de 1 de dezembro de 1965. Criando o Instituto de Pesquisa e Planejamento Urbano de Curitiba, com a Sigla IPPUC, e alterando a constituição de órgãos internos da Prefeitura Municipal. Curitiba.

Deschamps, M. V. (2004). Vulnerabilidade socioambiental na região metropolitana de Curitiba/PR (Tese de doutorado). Universidade Federal do Paraná, Curitiba.

Fachini, J. (1975). A significação social do planejamento urbano - estudo do caso de Curitiba (Dissertação de mestrado). Universidade Federal do Rio Grande do Sul, Porto Alegre.
Fernandes, A. (1979). Planejamento urbano de Curitiba: a institucionalização de um processo (Dissertação de mestrado). COPPE, Universidade Federal do Rio de Janeiro, Rio de Janeiro.

Firkowski, O. L. C. F. (2001). A nova territorialidade da indústria e o aglomerado metropolitano de Curitiba (Tese de doutorado). Faculdade de Filosofia, Letras e Ciências Humanas, Universidade de São Paulo, São Paulo.

Firkowski, O. L. C. F. (2009a). Considerações sobre o grau de integração da Região Metropolitana de Curitiba na economia internacional e seus efeitos nas transformações socioespaciais. In R. Moura, \& O. L. C. F. Firkowski (Eds.). Dinâmicas intrametropolitanas e produção do espaço na Região Metropolitana de Curitiba. Rio de Janeiro: Letra Capital, Observatório das Metrópoles/Observatório de Políticas Públicas do Paraná.

Firkowski, O. L. C. F. (2009b). Localização industrial e extensão urbana em Curitiba. In R. Moura, \& O. L. C. F. Firkowski (Eds.). Dinâmicas intrametropolitanas e produção do espaço na Região Metropolitana de Curitiba. Rio de Janeiro: Letra Capital, Observatório das Metrópoles/ Observatório de Políticas Públicas do Paraná.

Galvão, M. V., Faissol, S., Lima, O. B., \& Almeida, E. M. J. M. (1969). Áreas de pesquisa para determinação de áreas metropolitanas. Revista Brasileira de Geografia, 31(4), $53-128$

Garcia, F. E. S. (1993). Curitiba, imagem e mito: reflexão acerca da construção social de uma imagem hegemônica (Dissertação de mestrado). Programa de Pós-graduação em Planejamento Urbano, Instituto de Pesquisa e Planejamento Urbano e Regional, Universidade Federal do Rio de Janeiro, Rio de Janeiro.

Garcia, M. D. (1990). O MAB: Movimento de Associações de Bairros de Curitiba e Região Metropolitana e a construção de uma nova prática política (Dissertação de mestrado). Programa de Pós-graduação em Sociologia Política, Universidade Federal de Santa Catarina, Florianópolis.

Gonzáles Osório, H. H. (1984). Habitat urbano e alternativas de desenvolvimento: considerações sobre experiência de Curitiba (Tese de doutorado). Programa de Pós-graduação em Estudos do Desenvolvimento, Instituto Universitário de Estudos do Desenvolvimento, Curitiba.

Hardt, C. (2004). Gestão Metropolitana: consequências dos paradigmas das políticas públicas na qualidade ambiental do compartimento Leste da Região Metropolitana de Curitiba 
(Tese de doutorado). Programa de Pós-graduação em Meio Ambiente e Desenvolvimento), Universidade Federal do Paraná, Curitiba.

Instituto Brasileiro de Geografia e Estatística - IBGE. (1966). Esboço preliminar da Divisão do Brasil em regiões polarizadas. Rio de Janeiro: IBGE.

Instituto Brasileiro de Geografia e Estatística - IBGE. (1970). Censo demográfico de 1970. Rio de Janeiro: IBGE. Recuperado em 7 de julho de 2015, de http://biblioteca. ibge.gov.br/biblioteca-catalogo.html?view=detalhes\&id=769

Instituto Brasileiro de Geografia e Estatística - IBGE. (1980). Censo demográfico de 1980. Rio de Janeiro: IBGE. Recuperado em 7 de julho de 2015, de http://biblioteca.ibge. gov.br/biblioteca-catalogo.html?view=detalhes\&id=7310

Instituto Brasileiro de Geografia e Estatística - IBGE. (2010). Censo demográfico de 2010. Rio de Janeiro: IBGE. Recuperado em 7 de julho de 2015, de http://censo2010. ibge.gov.br/

Instituto Universitário de Pesquisas do Rio de Janeiro - IUPERJ. (1975). Dimensões do Planejamento Urbano de Curitiba: o caso de Curitiba (Vol. 2). Rio de Janeiro: Secretaria Geral do MINTER.

Leitão, S. R. (2002). O discurso do planejamento urbano em Curitiba: um enigma entre a prática e a cidade real (Dissertação de mestrado). Programa de Pós-graduação em Estruturas Ambientais Urbanas, Faculdade de Arquitetura e Urbanismo, Universidade de São Paulo, São Paulo.

Leitão, S. R. (2010). Inclusão do Excluído? Política de mobilidade e dinâmica do mercado de terras na expansão da Curitiba Metrópole (Tese de doutorado). Programa de Pós-graduação em Planejamento Urbano Regional, Faculdade de Arquitetura e Urbanismo, Universidade de São Paulo, São Paulo.

Lencioni, S. (2011). Referências analíticas para a discussão da metamorfose metropolitana contemporânea. In S. Lencioni, S. Vidal-Koppmann, R. Hidalgo, \& P. X. C. Pereira (Eds.). Transformações sócio-territoriais nas metrópoles de Buenos Aires, São Paulo e Santiago (pp. 51-64). São Paulo: Paim.

Lima, C. A. (2000). A ocupação de área de mananciais e os limites dos recursos hídricos na RMC: do planejamento à gestão ambiental urbana-metropolitana (Tese de doutorado). Programa de Pós-graduação em Meio Ambiente e Desenvolvimento, Universidade Federal do Paraná, Curitiba.
Millarch, A. (1987). Planejamento Regional com muita politicagem (pp. 13). Paraná: Jornal 0 Estado do Paraná.

Moura, R. (2009). Arranjos urbano-regionais no Brasil: uma análise com foco em Curitiba (Tese de doutorado). Programa de Pós-graduação em Geografia, Universidade Federal do Paraná, Curitiba.

Namur, M. (1976). El planeamiento urbano como processo: el Caso de Curitiba-PR (Dissertação de mestrado). Programa de Pós-graduação em Planejamento Urbano e Regional, Instituto de Planeamiento de Lima, Universidad Nacional de Ingenieria, Lima.

Namur, M. (1992). Estado e empresariado em Curitiba, a formação da cidade industrial (1973-1980) (Tese de doutorado). Programa de Pós-graduação em Estruturas Ambientais Urbanas, Faculdade de Arquitetura e Urbanismo, Universidade de São Paulo, São Paulo.

Nazareno, L. R. (2005). Redes Sociais e coalizão de governo em Curitiba 1985-2004. (Dissertação de mestrado). Faculdade de Filosofia, Letras e Ciências Humanas, Universidade de São Paulo, São Paulo.

Oliveira, D. (1995). A política do planejamento urbano: o caso de Curitiba (Tese de doutorado). Universidade Estadual de Campinas, Campinas.

Oliveira, D. (2000). Curitiba e o mito da cidade modelo. Curitiba: Editora da UFPR.

Organisation for Economic Co-operation and Development - OCDE. (2001a). Cities and regions in the new learning economy. Paris: OECD.

Organisation for Economic Co-operation and Development - OCDE. (2001b). Cities for citizens: improving metropolitan governance. Paris: OECD.

Paraná. Governo do Estado. (2005, 25 de agosto). Lei Estadual n. 111, de 11 de Agosto de 2005. Dispõe sobre o funcionamento das Regiões Metropolitanas do Estado do Paraná. Curitiba: Diário Oficial.

Paraná. Governo do Estado. Secretaria de Estado do Desenvolvimento Urbano do Paraná - SEDU. Coordenação da Região Metropolitana de Curitiba - COMEC. (2006). Plano de Desenvolvimento Integrado da RMC. Curitiba.

Pilotto, A. S. (2010). Área metropolitana de Curitiba: um estudo a partir do espaço intra-urbano (Dissertação de mestrado). Faculdade de Arquitetura e Urbanismo, Universidade de São Paulo, São Paulo. 
Piragis, C. M. E. (1988). Paraná concreto: fluxo e influxo da política economia financeira e seus reflexos no mercado imobiliário (Dissertação de mestrado). Programa de Pósgraduação em História, DEHIS/Universidade Federal do Paraná, Curitiba.

Polli, S. A. (2006). Curitiba, Metrópole Corporativa: fronteiras da desigualdade (Dissertação de mestrado). Programa de Pós-graduação em Planejamento Urbano e Regional, Instituto de Pesquisa e Planejamento Urbano e Regional, Universidade Federal do Rio de Janeiro, Rio de Janeiro.

Rickli, J., No. (2012). A perspectiva da ecologia política urbana no planejamento metropolitano de Curitiba: protegendo as águas e criando desigualdades (Dissertação de mestrado). Programa de Pós-graduação em Planejamento Urbano e Regional, Universidade Federal do Rio de Janeiro, Rio de Janeiro.

Rolim, M. C. M. B. (1985). Favelas, movimentos associativos e planejamento urbano em Curitiba (Dissertação de mestrado). Instituto Universitário de Pesquisas do Rio de Janeiro, Rio de Janeiro.

Santos, M. A. (1990). Metrópole corporativa fragmentada: o caso de São Paulo. São Paulo: Nobel.
Schussel, Z. G. L. (2006). A aglomeração metropolitana de Curitiba e as tendências contemporâneas do planejamento urbano (Tese de doutorado). Programa de Pós-graduação em Meio Ambiente e Desenvolvimento, Universidade Federal do Paraná, Curitiba.

Ultramari, C. (2001). Boas práticas e o fim das utopias: o $3^{\circ}$ setor e as agências internacionais de financiamento $e$ fomento (Tese de doutorado). Programa de Pós-graduação em Meio Ambiente e Desenvolvimento, Universidade Federal do Paraná, Curitiba.

Ultramari, C. (2005). O fim das utopias urbanas. São Paulo: Studio Nobel.

Ultramari, C., \& Moura, R. (1994). Metrópole: Grande Curitiba: teoria e prática. Curitiba: IPARDES.

Wilheim, J. (1990). Depoimento 3. In Instituto de Pesquisa e Planejamento Urbano de Curitiba - IPPUC. Memória de Curitiba Urbana (Vol. 5, pp. 25-38). Curitiba: IPPUC.

Recebido: Ago. 27, 2015

Aprovado: Dez. 22, 2015 